\title{
A comparison of maze escape behaviors of two species of the shore crab (Hemigrapsus)
}

\author{
LOWELL T. CROW \\ Western Washington University, Bellingham, Washington 98225
}

\begin{abstract}
Pacific shore crabs, Hemigrapsus nudus and Hemigrapsus oregonensis, were observed in a transparent Plexiglas maze as they escaped to a rock shelter. Measures were made of escape latency and number of zone crosses. $H$. nudus displayed a faster escape than $H$. oregonensis but was not significantly more active. The results were interpreted as of adaptive significance for $H$. nudus in the general occupation of a more exposed shoreline habitat than that of $H$. oregonensis.
\end{abstract}

It has been noted that Hemigrapsus nudus and Hemigrapsus oregonensis often occur together on Pacific Coast beaches, but that $H$. nudus is more likely to be found in exposed rocky places, whereas $H$. oregonensis is more typical of protected and quieter waters (Dehnel, 1960): Using a laboratory study quadrate made up of an artificial shoreline with gradations in substratum texture from mud to coarse rock, Crow and Heath (Note 1) found that $H$. nudus generally sought the higher rocky areas and $H$. oregonensis tended to frequent the muddier, wetter regions of the tank.

Thus, although behavioral differences apparently do exist between these closely related species, these differences usually have not been investigated in a controlled laboratory situation in the sense of determining the possible adaptive significance of specific responses that may differ between the two. The present study represents an attempt to explore such behavioral distinctions using a maze escape situation for crabs brought directly into the laboratory from the beach.

\section{METHOD}

Subjects

Nine male $H$. oregonensis (Dana) and 12 male $H$.nudus (Dana) shore crabs were used. The mean carapace width of $H$. oregonensis was $18.3 \mathrm{~mm}$, and for $H$. nudus, it was $18.5 \mathrm{~mm}$. The crabs were collected directly prior to each observation at Shannon Point near the Sundquist Marine Station, Anacortes, Washington, and they were returned to the beach immediately thereafter. Excluding November and December, observations were made between 9:00 a.m. and 3:00 p.m. at each month of the year. Due to a high variability of locomotor activity noted in Hemigrapsus (Symons, 1964), males alone were used.

\begin{abstract}
Apparatus
A $23 \times 32 \mathrm{~cm}$ Plexiglas maze, elevated $6.3 \mathrm{~cm}$ above the table, was used (Figure 1). Offset Plexiglas partitions provided a two-choice-point path to a rock shelter made from beach stones selected to fit the box end. A removable Plexiglas top was fitted over the entire maze. With the exception of the rock area, there were no opaque surfaces within the maze. A .1-sec stopwatch was used to time each run.
\end{abstract}

\section{Procedure}

Crabs were collected from the beach, brought into the laboratory in a beaker, and placed in the maze at the starting

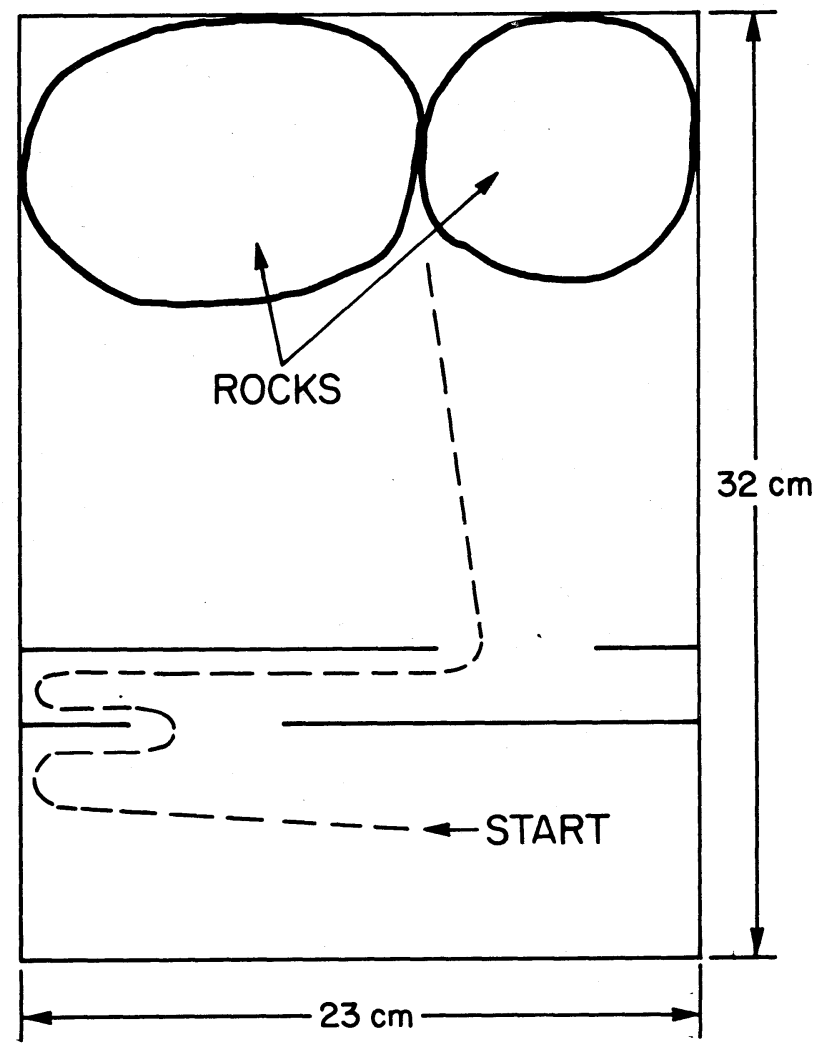

Figure 1. The maze pattern. Dashed line represents most frequent escape path and escape location.

point. Measures were made of time to reach the rocks (escape latency), escape route, and number of 28 arbitrarily assigned zone crosses (symmetrical crosshatches) depicted on a drawing near the data sheets. Initially, a 1-h observation period was used, but this was later reduced to $15 \mathrm{~min}$. Data reported here are based on a 15-min observation period common to all runs.

\section{RESULTS AND DISCUSSION}

Figure 1 shows the pattern of the maze, the typical escape route, and the escape location of $87 \%$ of the $H$. nudus run and $78 \%$ of the $H$. oregonensis. The mean escape latency was $129.5 \mathrm{sec}$ for $H$. nudus and $361.3 \mathrm{sec}$ 
for $H$. oregonensis. These data were transformed into logs and subjected to $t$ tests, which revealed a significant mean difference $[t(16)=2.44, p<.05]$. Three crabs did not escape within the 15-min observation period and were discarded from the analysis.

Beginning with the 2nd observation day (Crab 2), as a measure of general activity, the number of zone crosses during the 15-min observation period were counted. The mean number of crosses was 28.3 for H. nudus and 21.5 for $H$. oregonensis. These differences were not significant $[\mathrm{t}(15)=.99, \mathrm{p}>.3]$.

It would appear that in the present situation, $H$. nudus, while no more likely to move than $H$. oregonensis, displayed a faster locomotion, on the average, in its initial escape behavior. Since the escape was from visual stimuli, and since $H$. nudus tend to occupy higher, more exposed shoreline areas, the quicker reaction is not surprising, as it would seem to be adaptive as an antipredatory response. Further, the more rapid escape of
H. nudus does not appear to be due to a greater activity of this species, but rather, to a more specific response to visual stimuli.

\section{REFERENCE NOTE}

1. Crow, L., \& Heath, W. Comparative behavior of two species of the shore crab (Hemigrapsus). Paper presented at the meetings of the American Association for the Advancement of Science, Berkeley, Calif., 1965.

\section{REFERENCES}

Dehnel, P. A. Effect of temperature and salinity on the oxygen consumption of two intertidal crabs. Biological Bulletin, 1960, 118, 215-249.

Symons, P. E. K. Behavioral responses of the crab Hemigrapsus oregonensis to temperature, diurnal light variation, and food stimuli. Ecology, 1964, 45, 580-591.

(Received for publication April 20, 1981.) 